\section{Case Reports in Oncology}

\title{
Role of Imaging in Diagnosis of a Rare Hepatosplenic Gamma Delta T-Cell Lymphoma during Pregnancy: A Case Report and Review of Literature
}

\author{
Reda R.H. Youssef ${ }^{a} \quad$ Amr Elmahdy ${ }^{b}$ Samah Kohla ${ }^{c}$ Feryal Ibrahim ${ }^{c}$ \\ Ahmed Saied Sabry ${ }^{a}$ Amal Alobaidly ${ }^{a} \quad N^{2}$ al Saloum ${ }^{a}$ \\ aDepartment of Clinical Imaging, Women's Wellness and Research Center, Hamad Medical \\ Corporation, Doha, Qatar; ${ }^{b}$ Department of Clinical Imaging, Hamad Medical Corporation, \\ Doha, Qatar; 'Department of Lab Medicine and Pathology, Hematology Section, NCCR, \\ Doha, Qatar
}

\section{Keywords}

Pregnancy $\cdot$ Lymphoma $\cdot$ HSTCL $\cdot$ Ultrasonography

\begin{abstract}
Hepatosplenic $\gamma \delta$ T-cell lymphoma (HSTCL) is a very rare peripheral T-cell lymphoma characterized by extranodal infiltration of mature malignant post-thymic T-lymphocytes into sinusoids of the liver and spleen without lymphadenopathy and significant cytopenias. It is an aggressive form of lymphoma, resistant to the conventional chemotherapy. We report a case of HSTCL in pregnancy. Because this condition is an extremely aggressive and rare entity, data from these cases can help confirm the most suitable treatment regimen and timing of initiation. The role of ultrasound and magnetic resonance imaging in the diagnosis has been discussed. HSTCL is a rare entity of T-cell lymphoma, uncommon in female patients and very rarely reported during pregnancy.




\section{Introduction}

Hepatosplenic $\gamma \delta$ T-cell lymphoma (HSTCL) is a very rare peripheral T-cell lymphoma characterized by extranodal infiltration of mature malignant post-thymic T-lymphocytes into sinusoids of the liver and spleen without lymphadenopathy and significant cytopenias [1].

The peak incidence is in adolescents and young adults, and it is more common in males. Up to $20 \%$ of HSTCL arise in the setting of chronic immune suppression, most commonly solid organ transplantation or prolonged antigenic stimulation [2].

Because of the aggressive course of the disease and resistance to conventional chemotherapy, the prognosis for patients with HSTCL is poor, with a median survival of 12-14 months [3].

\section{Case Report}

In this study, we present the case of a 36-year-old G3P2 patient, with no past medical illnesses. She presented at 8 weeks of pregnancy for follow-up of her laboratory results. Complete blood count results showed pancytopenia with a hemoglobin level of $11 \mathrm{~g} / \mathrm{dL}$, white blood cell count of $2.0 \times 10^{3} / \mu \mathrm{L}$, and platelet count of $97 \times 10^{3} / \mu \mathrm{L}$. The patient was referred for ultrasound of the abdomen.

Ultrasound of the abdomen was performed and revealed evidence of hepatosplenomegaly, with a liver span of $16.6 \mathrm{~cm}$ and a spleen span of $21 \mathrm{~cm}$. Both were showing normal echotexture with no evidence of focal lesions detected. The transabdominal ultrasound confirmed the single uterine viable pregnancy. An incidental finding of right renal angiomyolipoma was noted (Fig 1A-D).

Bone marrow examination was done in July 2018. Flow cytometry performed on bone marrow aspirate revealed 8\% CD3-positive T-cells including 5\% T-cells expressing CD5, CD7, CD2, and TCR $\alpha / \beta$ with a CD4:CD8 ratio of 1.4:1. The T-cells included a subpopulation of CD4/CD8 double-negative $\gamma \delta$ T-cells comprising 3\% and expressing CD2 and CD7 with a lack of CD5 expression. Bone marrow biopsy was normocellular for age with trilineage hematopoiesis. CD3 IHC stain revealed scattered CD3 positivity with few small clusters. Viral markers of HIV, HBV, HCV, CMV, EBV, adenovirus, and rubella were all negative. Syphilis screening and schistosomiasis serology were negative.

The patient was scheduled for a follow-up ultrasound, which showed a further increase in the liver span up to $21.7 \mathrm{~cm}$ and a further increase in the splenic span to $25.4 \mathrm{~cm}$.

A multidisciplinary team meeting was held, and the decision was made to admit the patient for an elective Cesarean section at 34 weeks. A delivery of a $2.4-\mathrm{kg}$ baby with cephalic presentation was made.

PET/CT scan was done which showed the liver reaching $30 \mathrm{~cm}$ in the craniocaudal span and the spleen reaching $27 \mathrm{~cm}$ in the maximal craniocaudal span. The spleen showed moderately increased uptake (SUVmax 5.8) at its upper medial, lower ventral, and lateral aspects (Fig. 2A-D).

Abdominal MRI scan was done, which showed a liver span of $30.1 \mathrm{~cm}$ and a spleen span of $31.7 \mathrm{~cm}$ (Fig. 3A, B).

Percutaneous ultrasound-guided liver biopsy was done in December 2018 and specimens were sent for histopathology, which proposed a diagnosis of T-cell lymphoma, most probably HSTCL. 
For a second opinion, the specimens were sent to Mayo Clinic which supported the pathological diagnosis of CD30- and PD1-negative HSTCL.

A second staging bone marrow examination was done in December 2018. Peripheral blood showed severe pancytopenia. Bone marrow aspirate was cellular with increased megakaryocytes and erythroid hyperplasia with mildly reduced granulocytic cells and showed 4\% abnormal looking small lymphoid cells with dense chromatin and irregular nuclear contour (Fig. 4A). Histiocytes were prominent and a substantial number showed hemophagocytosis (Fig. 4B).

Flow cytometry on bone marrow revealed $12 \%$ T-cells expressing CD3, CD7, and CD2 and included a subpopulation (7\%) expressing CD56, CD16, CD38, cTIA, and TCR $\gamma \delta$ (dim) with no significant expression of CD5, CD4, CD8, CD10, CD57, or CD25 (Fig. 5).

Bone marrow biopsy reflected cellular to mildly hypercellular marrow $(\sim 50-80 \%)$ showing trilineage hemopoiesis with increased megakaryocytes and erythroid precursors and showed abnormal T-cell infiltration, predominantly intrasinusoidal as highlighted by immunostain; positive for CD3, CD2, CD7, CD56 and negative for CD5, CD8 CD4, CD57, and granzyme B. Immunostain for CD68 highlighted increased monocytes/macrophages (Fig. 6, Fig. 7).

The overall findings were indicative of bone marrow involvement by T-cell neoplasm (HSTCL) with features of hemophagocytic lymphohistiocytosis.

Follow-up bone marrow examination was performed. Peripheral blood showed mild anemia. Bone marrow aspirate was cellular with trilineage hematopoiesis. Flow cytometry on bone marrow aspirate showed 3\% T-cells including $<0.1 \%$ CD4/CD8 double-negative T-cells and the majority expressed TCR $\gamma \delta$.

Bone marrow biopsy was cellular with trilineage hematopoiesis. IHC stain highlighted many scattered T-cells with few clusters and small aggregates positive for CD3 with a mixture of CD4- and CD8-positive cells. The provided specimen showed no obvious morphologic or immunophenotypic evidence of bone marrow involvement by T-cell lymphoma (complete remission).

The patient received multiple cycles of chemotherapy during this period. Eventually, she underwent open splenectomy and allogenic bone marrow transplantation from a matching sibling donor.

\section{Discussion}

HST is a relatively rare lymphoid neoplasm that belongs to the clinically heterogeneous group of PTCLs. Because of its unique clinical manifestations, histologic pattern of infiltration, and immunophenotypic features, it has been recognized as a distinct entity in the World Health Organization Classification of Lymphoid Malignancies [4].

According to a study by Glaser et al. [1] published in 2012, only 150 cases have been reported in the literature since the initial description by Farcet and Gaulard in 1990.

Approximately $10-20 \%$ of affected patients have a prior history of being immunocompromised, including renal transplantation, heart transplantation, Hodgkin's lymphoma, acute myelogenous leukemia, inflammatory bowel disease, and malaria infection [5].

On the contrary, the development of lymphoma during a pregnancy is rare, occurring in only 1 of 1,000-6,000 deliveries [6].

According to a case report by Niitsu et al. [7] in 2004, the majority of pregnancy-associated lymphomas were either Hodgkin's lymphoma or B-cell lymphoma, while T-cell lympho- 


\section{Case Reports in Oncology}

ma has rarely been reported. To the best of their knowledge at the time of their publication, their case was the first report of pregnancy-associated HSTCL in the English literature [7].

\section{Conclusion}

HSTCL is a rare, aggressive entity and its association with pregnancy is extremely rare and seldom reported. The radiological findings, the degree of hepatosplenomegaly, and the rate of enlargement in serial imaging are characteristic to this entity. Histopathological analysis is always necessary to confirm the diagnosis.

\section{Acknowledgement}

The authors would like to acknowledge QNL for support.

\section{Statement of Ethics}

The authors have no ethical conflicts to disclose. The case report was conducted ethically in accordance with the guideline of the Medical Research Center (MRC) of Hamad Medical Corporation (HMC), and after obtaining their approval. Informed consent was provided by the patient to publish the case.

\section{Disclosure Statement}

The authors declare that they have no relevant financial interests.

\section{Funding Sources}

This manuscript was funded by QNL.

\section{Author Contributions}

Dr. Amr Elmahdy did the literature review and wrote the radiology part of the manuscript. Dr. Reda Ramadan, Dr. Ahmed Sabry, Dr. Nehal Saloum, and Dr. Amal Alobaidly reviewed and edited the radiology part of the manuscript. Dr. Samah Kohla and Dr. Feryal Ibrahim wrote, reviewed, and supervised the hematology/oncology part of the manuscript.

\section{References}

1 Glaser M, Goropevšek A, Kavalar R, Glaser A. Hepatosplenic gamma-delta T-cell lymphoma in a female patient after delivery. Hematol Rep. 2012 Jan;4(1):e4.

2 Madabhavi I, Modi G, Panchal H, Patel A, Revannasiddaiah S, Anand A, et al. Hepatosplenic Gamma Delta TCell Lymphoma (HSGDTCL): Two Rare Case Reports from Western India. Int J Hematol Oncol Stem Cell Res. 2017 Oct;11(4):296-300. 
 Oncology}

3 Steurer M, Stauder R, Grünewald K, Gunsilius E, Duba HC, Gastl G, et al. Hepatosplenic gammadelta-T-cell lymphoma with leukemic course after renal transplantation. Hum Pathol. 2002 Feb;33(2):253-8.

4 Khan WA, Yu L, Eisenbrey AB, Crisan D, al Saadi A, Davis BH, et al. Hepatosplenic gamma/delta T-cell lymphoma in immunocompromised patients. Report of two cases and review of literature. Am J Clin Pathol. 2001 Jul;116(1):41-50.

5 Falchook GS, Vega F, Dang NH, Samaniego F, Rodriguez MA, Champlin RE, et al. Hepatosplenic gamma-delta T-cell lymphoma: clinicopathological features and treatment. Ann Oncol. 2009 Jun;20(6):1080-5.

6 Pohlman B, Macklis RM. Lymphoma and pregnancy. Semin Oncol. 2000 Dec;27(6):657-66.

7 Niitsu N, Kohri M, Togano T, Nakamine H, Nakamura S, Iwabuchi K, et al. Development of hepatosplenic gammadelta T-cell lymphoma with pancytopenia during early pregnancy: a case report and review of the literature. Eur J Haematol. 2004 Nov;73(5):367-71.
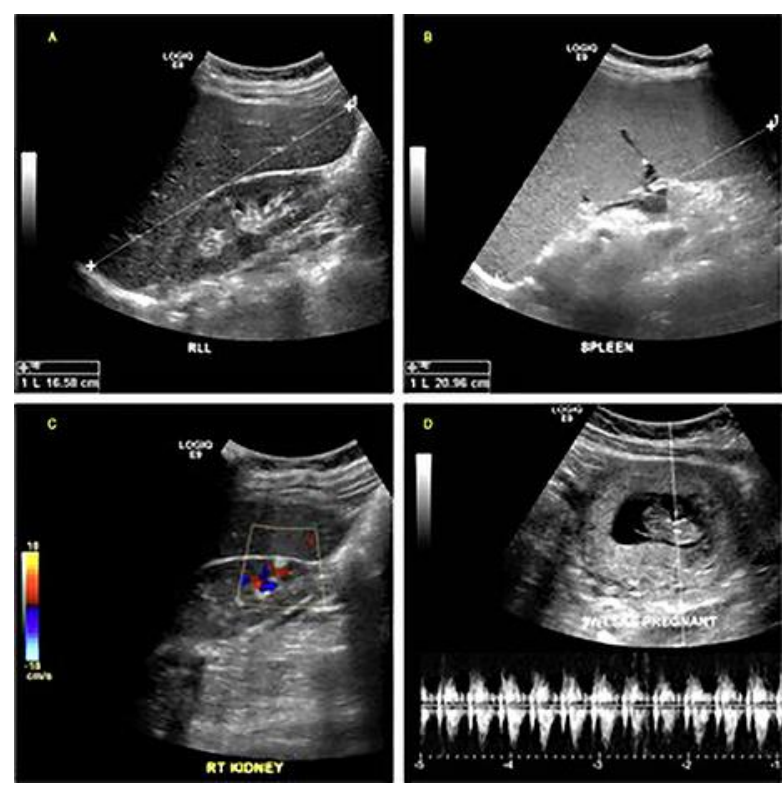

Fig. 1. A-D Transabdominal ultrasound of the abdomen and pelvis at 9 weeks' gestation. A Liver span of $16.6 \mathrm{~cm}$. B Spleen span of $21 \mathrm{~cm}$. C Right renal angiomyolipoma. D Intrauterine single viable pregnancy. 


\section{Case Reports in Oncology}

\begin{tabular}{l|l}
\hline Case Rep Oncol 2019;12:935-943 \\
\hline DOI: 10.1159/000504568 & $\begin{array}{l}\text { @ 2019 The Author(s). Published by S. Karger AG, Basel } \\
\text { www.karger.com/cro }\end{array}$ \\
\hline
\end{tabular}

Youssef et al.: Role of Imaging in Diagnosis of a Rare Hepatosplenic Gamma Delta T-Cell Lymphoma during Pregnancy: A Case Report and Review of Literature
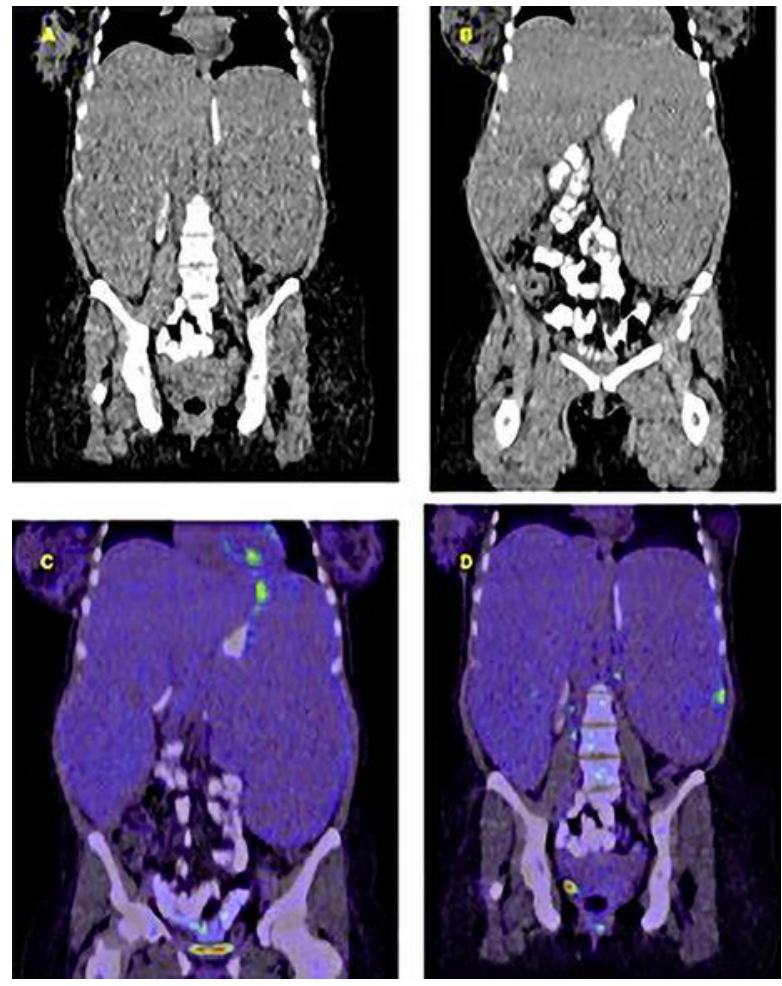

Fig. 2. PET/CT scan of the abdomen and pelvis. A Liver span of $30 \mathrm{~cm}$. B Spleen span of $27 \mathrm{~cm}$. C, D Moderately increased uptake of the upper medial and lower ventral and lateral aspects of the spleen.
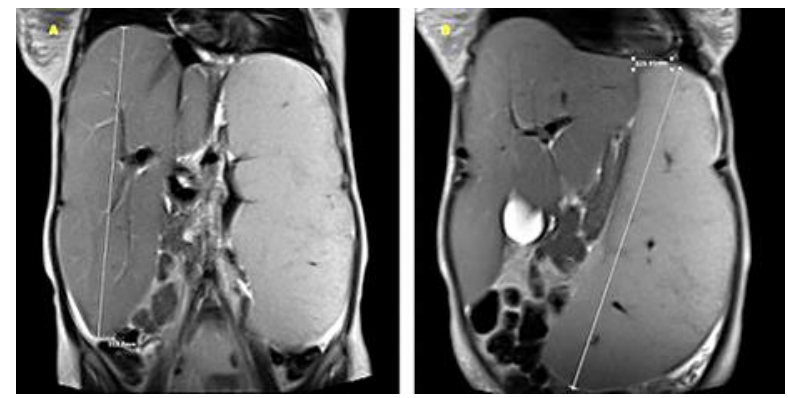

Fig. 3. Magnetic resonance imaging of the abdomen and pelvis. A Liver span of $31 \mathrm{~cm}$. B Spleen span of $33 \mathrm{~cm}$. 


\section{Case Reports in Oncology}

\begin{tabular}{l|l}
\hline Case Rep Oncol 2019;12:935-943 \\
\hline DOI: 10.1159/000504568 & $\begin{array}{l}\text { @ 2019 The Author(s). Published by S. Karger AG, Basel } \\
\text { www.karger.com/cro }\end{array}$ \\
\hline
\end{tabular}

Youssef et al.: Role of Imaging in Diagnosis of a Rare Hepatosplenic Gamma Delta T-Cell Lymphoma during Pregnancy: A Case Report and Review of Literature

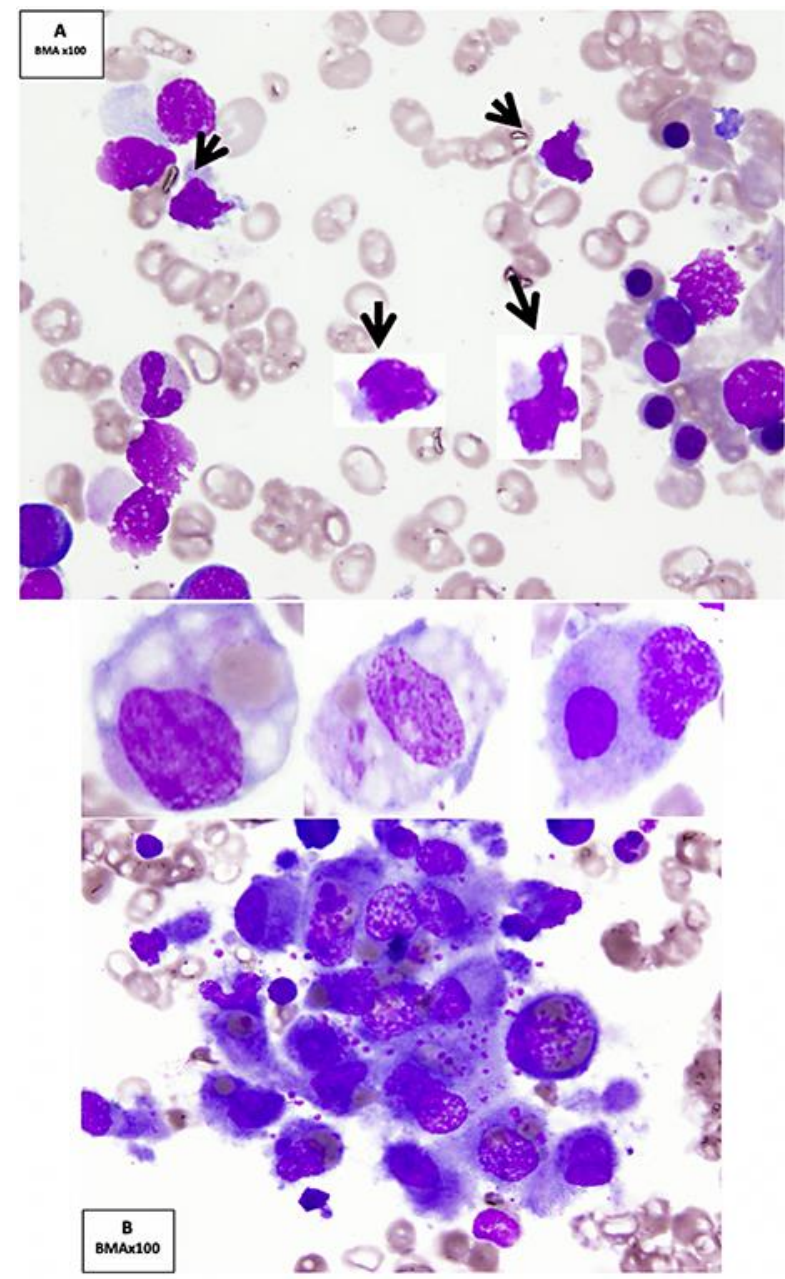

Fig. 4. Bone marrow aspirate (composite) showing abnormal looking small lymphoid cells (arrows) with dense chromatin and irregular nuclear contour (Wright-Giemsa) $\times 100$ (A) and prominent histiocytes with features of hemophagocytosis (Wright-Giemsa) ×100 (B). 


\section{Case Reports in Oncology}
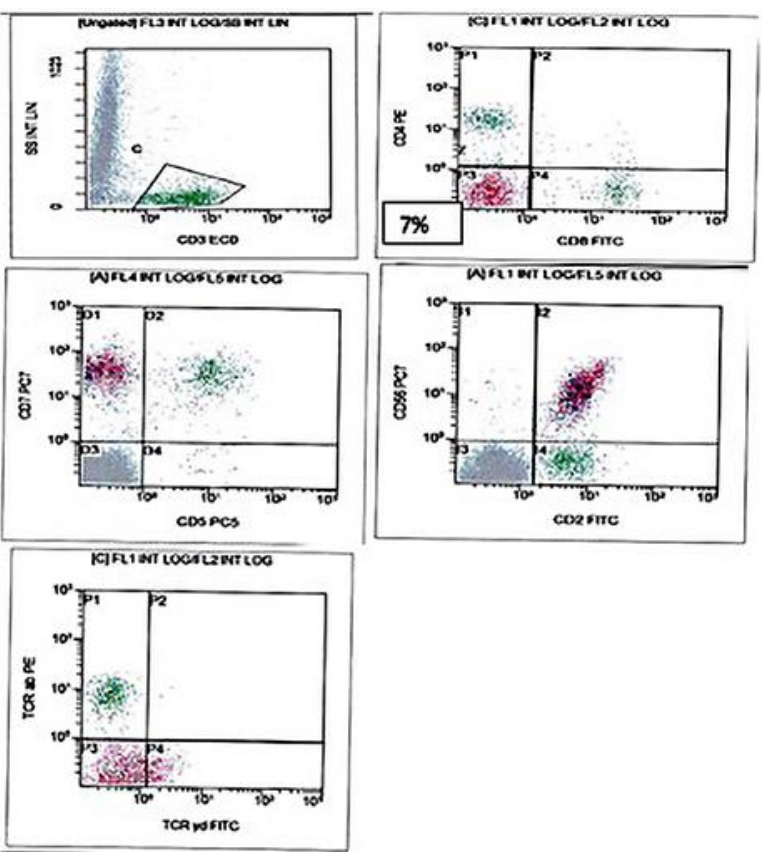

Youssef et al: Role of Imaging in Diagnosis of a Rare Hepatosplenic Gamma Delta T-Cell Lymphoma during Pregnancy: A Case Report and Review of Literature

Fig. 5. Flow cytometry dot blot showing a subpopulation of T-cells comprising 7\% (shown in red) expressing CD3, CD2, CD7, CD56, and TCR $\gamma / \delta$ (dim) with no significant expression of CD5, CD4, or CD8.

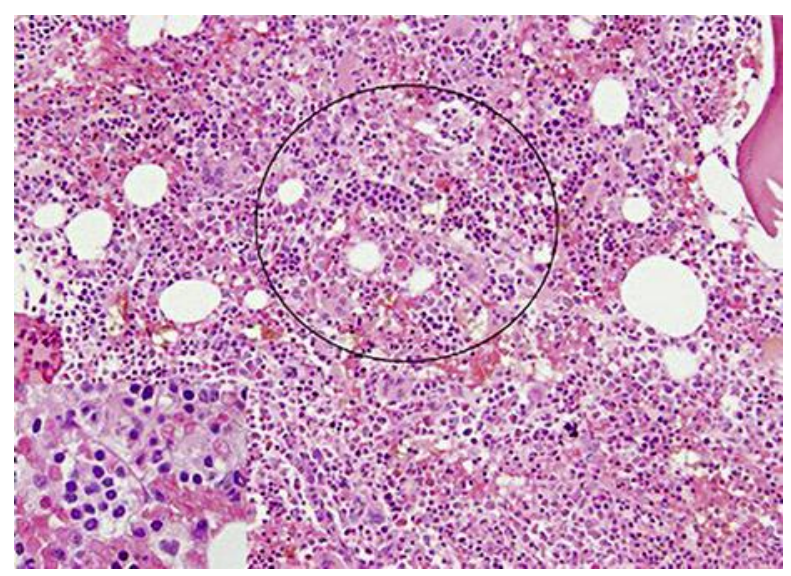

Fig. 6. H\&E stain: bone marrow core biopsy showing mild hypercellularity and abnormal T-cell infiltrate, predominantly intrasinusoidal. 
Youssef et al:: Role of Imaging in Diagnosis of a Rare Hepatosplenic Gamma Delta T-Cell Lymphoma during Pregnancy: A Case Report and Review of Literature

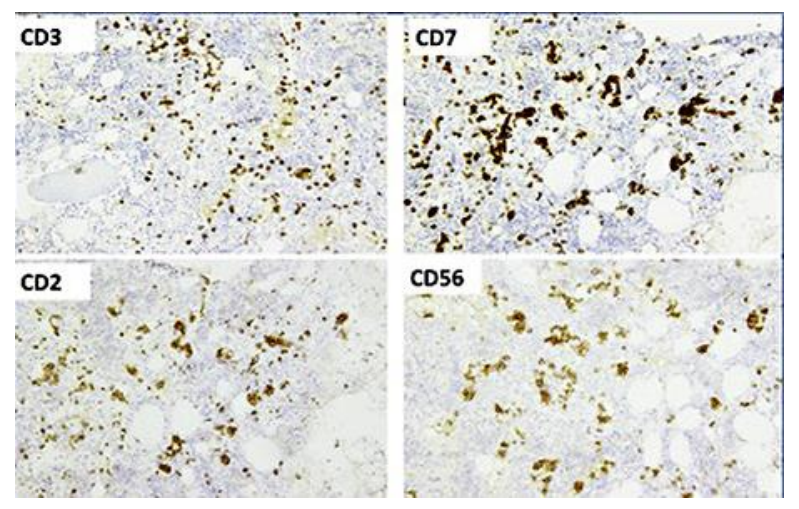

Fig. 7. Immunohistochemical staining for the abnormal T-cell infiltrate, predominantly intrasinusoidal, positive for CD3, CD7, CD2, and CD56. 